\title{
Mobile Game Development for Children with Down Syndrome
}

https://doi.org/10.3991/ijim.v14i20.16573

\author{
Ceren Cubukcu ${ }^{\bowtie}$, Murat Kaan Canbazoglu, Yigit Ozerdem \\ Maltepe University, Istanbul, Turkey \\ cerencubukcu@maltepe.edu.tr
}

\begin{abstract}
Children with diagnosis of down syndrome has different kinds of personalities, mental states, and talents similar to other children. The key point is that every child needs proper support at the right time. There are options like special education programs, physical and other therapies, and play groups. However, there are not any electronic games to support the education and improvement of these children. The goal of this study is to develop a mobile game for children with down syndrome, in order to help them learn everyday knowledge by using a mobile device such as a smart phone or a tablet. In most cases pedagogues use puzzle or paper-based card games to teach these children the necessary knowledge they need to maintain their lives. This study aims to optimize the learning process of children with down syndrome by providing educators electronic games they can use to teach them in a mobile application which will enrich the teaching process in addition to update their teaching methods to Industry 4.0 standards.
\end{abstract}

Keywords - Software development, game development, industry 4.0, children with down syndrome, m-learning, mobile based game learning

\section{$1 \quad$ Introduction}

The world is changing significantly since the midst of 18 th century. Industry Evolution, which can also be called Industry 1.0 era, has started this change and today it slowly evolved to Industry $4.0[1,2]$. Industry 4.0 is the period of innovations and knowledge. Industry 4.0, was first used in Germany in 2011 in the world's biggest industry expo in Hannover Messe [2, 3]. It was actually a project based on hightechnology strategies and started by the German government. It includes cyberphysical systems, Internet of things (IoT), Internet of services (IoS), Augmented reality, big data analytics and cloud information systems $[4,5,6]$.

Industry 4.0 brings changes in education as well and therefore, a new term called Education 4.0 came into our lives. It will change the emphasis from teaching to learning by placing the student at the centre of the process in addition to utilizing the advantages of the developing technology and becomes more digital through the forms of online teaching materials [7]. Educators of all kind need to digitize their materials in order to catch up with the trends of today. Unfortunately, there are no digital 
material for the education of children with down syndrome. Therefore, the educators of these children are lacking the necessary materials of raising them according to a digital world. In this study, it is aimed to develop a mobile game for the education of children with down syndrome. This mobile game will enrich the teaching process of educators along with updating their teaching methods to Education 4.0 standard.

Education 4.0 is integrated with M-learning. M-learning, meaning learning with the help of mobile tools, started to get popular among educators since the invention of smartphones. M-learning is part of e-learning in which educators benefit the advantages of internet [8]. Thus, educators do not need a physical classroom and can teach the children whenever and wherever they want. M-learning also provides JustIn-Time learning experience or learning right where the knowledge is necessary [9]. This is a great convenience for the educators of children with down syndrome since they come across with difficulties learning in a regular classroom setting. A mobile game application will give the educators the freedom they need in their teaching activities. It will also give freedom to the children with down syndrome for their learning activities because people with disabilities have a low level of independence and they are mostly dependent on others for many activities. This feeling of dependence is certainly disturbing and can reduce the enthusiasm of learning of persons with disabilities [10].

The trend of utilizing computer and video games for education is also on the rise for the past few years [11]. Games have the ability of keeping people in different conditions dedicated and concentrated on a task for a long period of time [12]. Moreover, studies show that videogames can be used to help students take active roles and learn via experience instead of memorizing the facts [13 - 17]. Players of video games feel more active and part of that world while in the game. This helps them to get deeper knowledge about the field of that study. However, the downside of gamebased learning is that developing a video game can be very costly depending on the graphics and program that is being used. In this study, it is preferred to develop the application of a puzzle game. Children with down syndrome play the offline version of this puzzle game for education purposes. By converting this puzzle game to an application, educators will have the comfort of not carrying the puzzles with them all the time.

\section{Related Work}

When M-learning is combined with video games, the concept of Game Based Mobile Learning has been founded. In an educational point of view, using both approaches provide a lot of advantages to educators. Mobility provides the independence of educational space and video games offer a fun way of teaching. Games for mobile devices are simpler by nature and thus, easier to program [18]. Therefore, in this study, a mobile game application is preferred to develop for children with down syndrome.

There are not many electronic games for children with special need. There is an application called Otsimo which is an educational mobile game application developed 
for children with autism. The purpose of games in the application is improving children's reading, writing, communication, speaking and math skills. Otsimo delivers reports and analyses about the improvement of children so that the parents can follow their educational development and actively take part in this growth at the same time helping the children's education [19]. Parents are the "experts" of their child, they know him/her better than anyone else and therefore, can provide any information that will be valuable in their child's education and therapeutic approach [20].

Otsimo has two separate modules. These are family and child modules. The child module has educational games for the children who need special education. Otsimo contains more than sixty games that assist children to learn core skills such as reading, writing, vocabulary and mathematic. On the other hand, Otsimo Family module is designed to allow families to monitor the progress of their children and actively take part in the process. They can access their children's game performances and developments through daily / weekly / monthly reports and statistics [19].

There is another application called MITA for autism language and cognitive therapy for children from 5 years and under. Although MITA is not solely a gaming application, it has 9 types of games to help children learn how to mentally integrate, notice and report multiple visual cues presented simultaneously at the features of an object [21]. Happy Therapy which is a developmental or behaviour disorders therapy application also includes games that support the therapy of the child with autism [21].

Nintendo Wii is also being used for the development of children with special need. According to a study made by Berg et. al. in 2012 [22], a child aged 12-year-old with a diagnosis of down syndrome and with limited Wii exposure was asked to play Wii games for 8 weeks at home 4 times each week for 20 minutes each session. The child's family also participated to these games. The child selected 4 different games to play. Working on the skills repeatedly associated with these games resulted in improvements of the child's postural stability, 2nd edition balance, BruininksOseretsky Test of Motor Proficiency, upper-limb coordination, limits of stability, running speed, manual dexterity and agility standard scores [22].

It can be understood from the study that Nintendo Wii is helpful for the motor improvement of children with down syndrome. However, there is a lack of electronic game for the educational growth of children with down syndrome. This study adds to current literature by providing the foundation of a mobile game for children with down syndrome.

\section{$3 \quad$ Methodology}

This research studies the development of a mobile application for children with down syndrome. System Architecture is very significant part of this study. Therefore, the overview of the system is explained using a flowchart. This can be seen below in Figure 1. According to the below Figure 1, the mobile game has two parts. One of them is the educational part and the other one is the leisure part. Both parts have different kinds of games according to their categories. In the educational part, the game is suited to the educational improvement of the children with down syndrome. 
For the aim of this paper, it will be focused on the educational part of the application in order to help the lecturers of children with down syndrome. In the leisure part, the game is more suited towards having fun. It does not have any purpose for education. This can be any kind of game depending on the creativity and skillset of the developer.

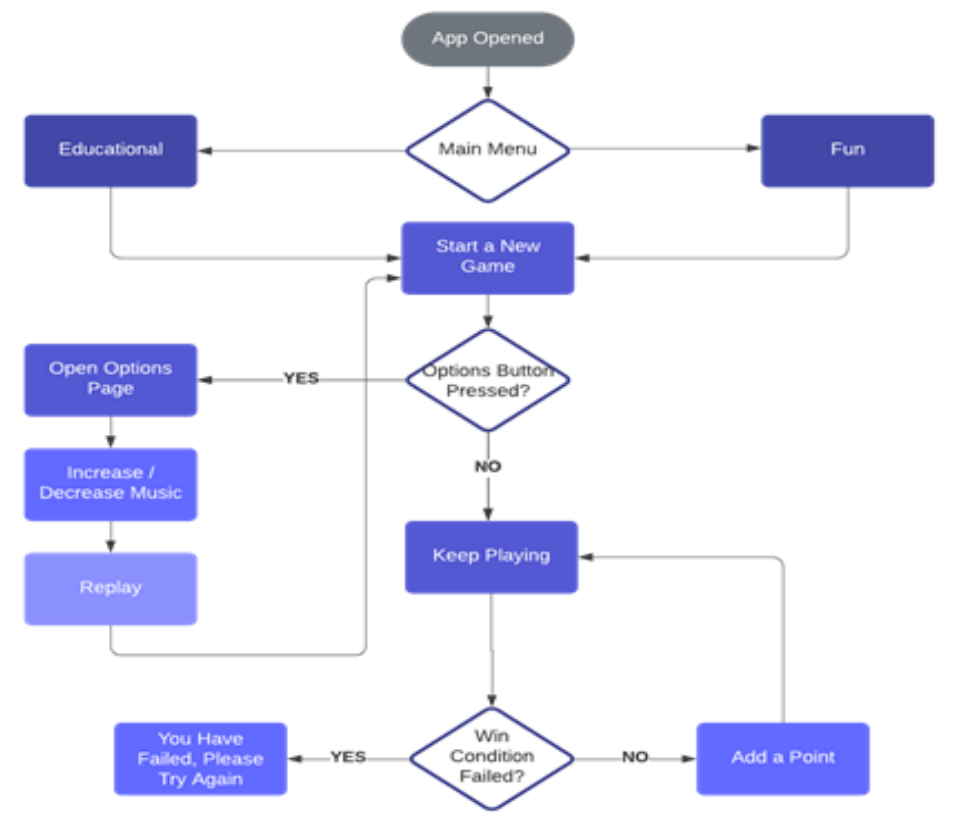

Fig. 1. Flowchart of the system

\subsection{Platform of the project}

In this study, Unity, AndroidOS, and Visual Studio Code is used to develop this mobile game. As it can be seen from the below Table 1, Android 4.3 is used for the operating system and Unity and $\mathrm{C \#}$ is used for the programming language.

Table 1. The Platform of the System

\begin{tabular}{|l|l|}
\hline \multicolumn{1}{|c|}{ OS (operating system) } & \multicolumn{1}{|c|}{ Android 4.3 (API Level 18) or Higher } \\
\hline Programming Languages & Unity and C \# \\
\hline
\end{tabular}

Android has been preferred for this study because Android OS is a Linux based open source operating system that was developed by Google in order to work on mobile devices such as tablets and smart-phones. Android OS can support 2D and 3D graphics, common audio and video formats as for multimedia support. In addition, Android OS can support multi-touch input, too and in its browser carries the Google Chrome's V8 JavaScript runtime [23]. 
Unity is preferred for the programming language. There are two main reasons that makes Unity so popular. First, it has lot of features together and second, it has the flexibility to make almost any game. Games like Pokemon Go, Heathstone, Rimworld and Cuphead are created using Unity. 2D along with 3D development can be done in Unity. Developers can use Unity 3D devices for 2D game development as well. Developers prefer it due to the integration of C\# scripting API in addition to integrated Visual Studio [24].

Artists prefer to use Unity too, due to its powerful animation tools which helps to make easy $3 \mathrm{D}$ cut scenes or create 2D animations from scratch. Furthermore, Unity 3D provides a free version to programmers who can develop games with Unity Personal without paying for the software with the condition that they make less than $\$ 100,000$ from games made with Unity. Unity 3D has many professional tools both for artists and programmers. Unity offers a workspace that joins artist-friendly tools with a component-driven design and provide pretty intuitive game development. Developers can also build impressive graphics across the board with physics-based materials, powerful shaders, high-resolution lighting systems and post-processing. Unity was built in $\mathrm{C}++$ and its performance developed significantly throughout the years [25].

Visual studio code: Visual Studio (VS) Code offers a lightning fast source code editor, good for daily use. It supports for many programming languages. "VS Code helps developers be productive with syntax highlighting, bracket-matching, autoindentation, box-selection, snippets, and more. Intuitive keyboard shortcuts, easy customization and community-contributed keyboard shortcut mappings let developers navigate the code with ease" [26].

Visual Studio Code has integral assistance for IntelliSense code refactoring, rich semantic code understanding, code completion and navigation. Once the coding gets hard, debugging also gets hard. "Debugging is often the one feature that developers miss most in a leaner coding experience." However, Visual Studio Code contains an interactive debugger. Thus, developers can go through the source code, review variables, see call stacks, and perform commands in the console. In order to accomplish common jobs and make ordinary workflows faster, VS Code also combines build and scripting tools [26].

\subsection{Test plan}

Having a test plan is an integral part of game development in order to eliminate the bugs within the code. Following are the test plan of all components that is followed in this study to verify the developed mobile games are working properly.

Alpha testing: Alpha testing is implemented when the game is still in the coding phase. It is applied along with parallel testing to confirm that the game is programmed without any problems and is working as intended with no crashes. In this phase, in order for the developers to fix the game, documentation of hardware and software failures are needed. [27]

Functionality testing: In functionality testing, as the name suggests, functionality of the system is being looked at with the intention of finding errors that may affect the 
end users of the game. This phase of testing checks whether the system is working as expected. "It is a complex testing method under the category of black-box testing technique. It takes more time to execute as testers look for game play issues, graphics issues, audio-visual issues, etc." Moreover, functionality testing ensures the efficiency of the installation, the working mode of the application, the support of the payment gateways, the ability of social networking and more [28].

Play testing: In this method, as the name suggests, testers play the game to investigate non-functional features like balance, fun factors, difficulty levels, etc. Also, in this phase, a pilot group of end users are selected and they play the incomplete versions of the game to see the work flow. "Key features include an integral part of game design and used commonly in PC games and character-playing games. It is more about judging the game rather than the facts. Main aim is to check whether a game works in a well-structured manner." [28].

\subsection{Developed application}

A mobile application is developed for the purposes of this study. In education part of the application, puzzle game is especially preferred since it is one of the most frequently used offline games in the education of children with down syndrome. Below there are screenshots from the application that is being developed. Soft and warm colours such as orange and blue are preferred in this application so as to draw attention, raise sensuality and make them more energetic. The user can select from two different kinds of activities in this application. The education section of the application will be explained in this study. When the user selects the education section, the below screen is shown as can be seen in Figure 2. The user needs to select a game type to start. There are 3 types of games; a matching card game for strengthening the memory of the child and 2 puzzle games. One of them is to warm the child up to the puzzle game and the other one is a more complex puzzle game for children with more abilities.

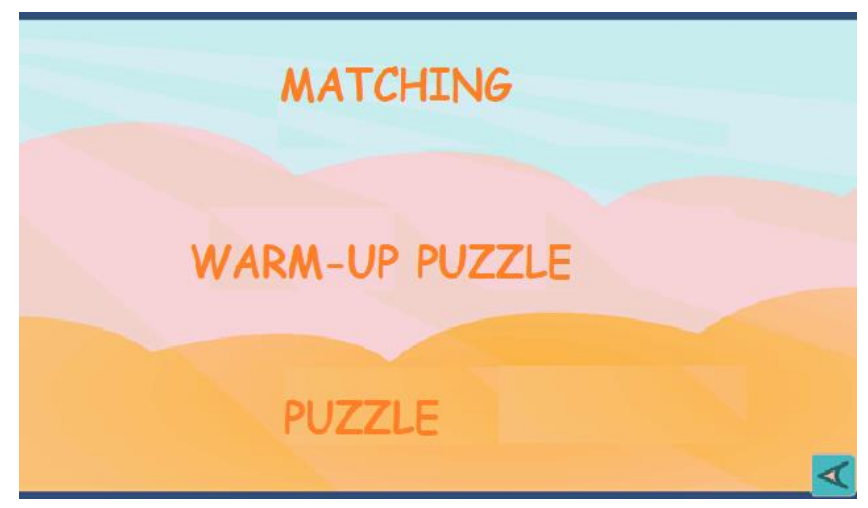

Fig. 2. The education section screen 
In Figure 3 below, it can be seen the successful matches of the user when playing the matching card game. The purpose of this game is to enhance the short term memory and the hand-eye coordination of the user, user can mute and unmute game sounds, replay or quit the puzzle by tapping the buttons to the upper right corner.

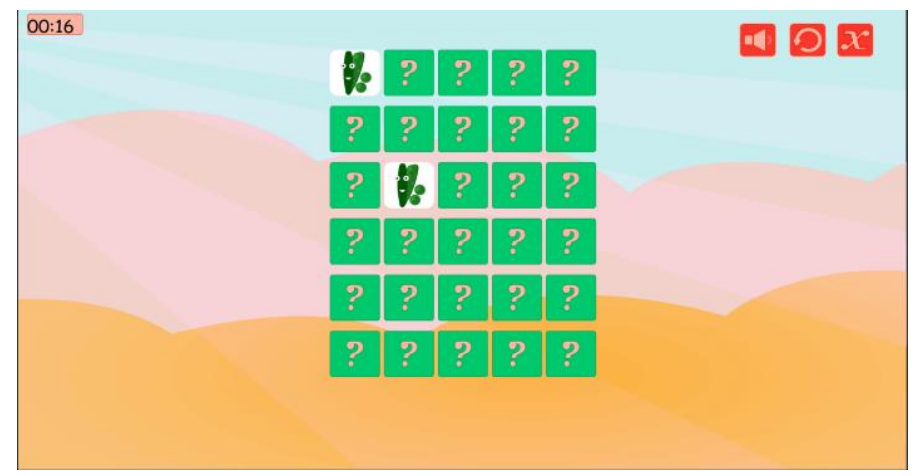

Fig. 3. The matching card screens

In warm-up puzzle game shown in Figure 4, the user needs to rotate puzzle pieces to form a complete picture. If the goal is achieved, a message will pop up and user can tap back button to go back and choose another game.

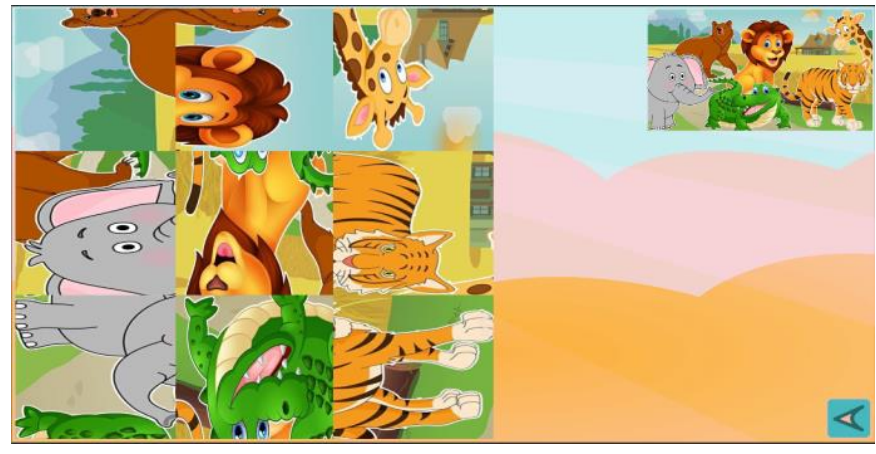

Fig. 4. Warm-up puzzle game

\section{Discussions}

In this study, a roadmap for the development of a mobile game application is tried to be explained. The importance of the concepts m-learning, game-based learning and mobile game-based learning is discussed for the educators. Mobile game-based learning will especially provide freedom to the educators of children with down syndrome in addition to enrich their teaching processes. Unfortunately, educators of these children still use offline materials in their teaching activities. There is a platform called Otsimo for the education of children with autism. Nintendo Wii is also being 
used for the motor development of children with down syndrome. However, there is neither an application nor a video game for the educational activities of children with down syndrome. This study contributes to the literature by providing a mobile application to the educators of children with down syndrome.

In this paper, the development of a mobile game application, for the children with down syndrome, is being explained. In the design process, a flowchart is being introduced to show the flow of the data within the application. According to this flowchart, two types of games are preferred in the application. One of them is an educational matching card and a puzzle game and the other one is a game played for leisure only. The preferred platform and programming language for this development is Android platform along with Unity and C\# programming languages. Visual Studio Code is also used for the source code editor of this application. A testing plan is also provided to test for the bugs of the application. Limitations of this study is that this application is only for the mobile devices with an Android operating system and it will not work in IOS devices. Future studies may include the development of different kinds of games and the digitization of offline teaching materials to an electronic platform. Moreover, other application may be developed for devices using IOS operating system.

\section{$5 \quad$ References}

[1] Puncreobutr, V. (2016). Education 4.0: New challenge of learning. St. Theresa Journal of Humanities and Social Sciences, 2(2).

[2] AYBEK, H. S. Y. (2017). Üniversite 4.0'a geçiş süreci: kavramsal bir yaklaşım. Açıköğretim Uygulamaları ve Araştırmaları Dergisi, 3(2), 164-176.

[3] Mosconi, F. (2015). The new European industrial policy: Global competitiveness and the manufacturing renaissance. Routledge.

[4] Lasi, H., Fettke, P., Kemper, H. G., Feld, T., \& Hoffmann, M. (2014). Industry 4.0. Business \& information systems engineering, 6(4), 239-242. https://doi.org/10.1007/s125 99-014-0334-4

[5] Ning, H., \& Liu, H. (2015). Cyber-physical-social-thinking space-based science and technology framework for the Internet of Things. Science China Information Sciences, 58(3), 1-19. https://doi.org/10.1007/s11432-014-5209-2

[6] State of Maturity Report, INDUSTRY 4.0 IMPLICATIONS FOR HIGHER EDUCATION INSTITUTIONS. (2017). Universities of the Future. European Union.

[7] FICCI \& Ernest-Young. (2018). University of future: Bringing education 4.0 to life. FICCI $\&$ Ernest and Young. Retrieved from http://ficci.in/spdocument/23043/higher-educationficci-Report.pdf https://doi.org/10.1525/9780520319127-011

[8] Georgiev, T., Georgieva, E., \& Smrikarov, A. (2004, June). M-learning-a New Stage of ELearning. In International conference on computer systems and technologiesCompSysTech (Vol. 4, No. 28, pp. 1-4). https://doi.org/10.1145/1050330.1050437

[9] Lavín-Mera, P., Moreno-Ger, P., \& Fernández-Manjón, B. (2008, November). Development of educational videogames in m-Learning contexts. In 2008 Second IEEE International Conference on Digital Game and Intelligent Toy Enhanced Learning (pp. 4451). IEEE. https://doi.org/10.1109/digitel.2008.21 
[10] Susilowati, N., Syafi'i, I., Aftina, A., Syahrul, A., Nogroho, D., \& Bitari, S. (2020). The Development of an Android-Based Dictionary for Blind. International Journal of Interactive Mobile Technologies (Ijim), 14(11), 76. https://doi.org/10.3991/ijim.v14i11.13 $\underline{875}$.

[11] Aldrich, C. (2005). Learning by doing: A comprehensive guide to simulations, computer games, and pedagogy in e-learning and other educational experiences. John Wiley \& Sons. https://doi.org/10.1145/1104985.1104993

[12] Prensky, M., Digital Game Based Learning. 2001, New York: McGraw-Hill.

[13] Becker, K. (2007). Pedagogy in commercial video games. Games and simulations in online learning: Research and development frameworks. Hershey. https://doi.org/10.4018/978-159904-304-3.ch002

[14] Gee, J.P., Good videogames and good learning: collected essays on video games. 2007, New York: Peter Lang Publishing.

[15] Jenkins, H., Klopfer, E., Squire, K., \& Tan, P. (2003). Entering the education arcade. Computers in Entertainment (CIE), 1(1), 1-11. https://doi.org/10.1145/950566.950591

[16] Squire, K., Game-Based Learning: An X-Learn Perspective Paper. Report for MASIE center: e-Learning Consortium. 2005.

[17] Van Eck, R. (2007). Building artificially intelligent learning games. In Games and simulations in online learning: Research and development frameworks (pp. 271-307). https ://doi.org/10.4018/978-1-59904-304-3.ch014

[18] Kurkovsky, S. (2013). Mobile game development: improving student engagement and motivation in introductory computing courses. Computer Science Edu, 23(2), 138-157. https://doi.org/10.1080/08993408.2013.777236

[19] Support | Otsimo. (2019). Retrieved 10 December 2019, from https://otsimo.com/en/categ ory/support

[20] Chaidi, I., \& Drigas, A. (2020). Parents' Involvement in the Education of their Children with Autism: Related Research and its Results. International Journal Of Emerging Technologies In Learning (Ijet), 15(14), 194. https://doi.org/10.3991/ijet.v15i14.12509.

[21] Xanthopoulou, M., Kokalia, G., \& Drigas, A. (2019). Applications for Children with Autism in Preschool and Primary Education. International Journal of Recent Contributions From Engineering, Science \& IT (Ijes), 7(2), 4. https://doi.org/10.3991/ijes.v7i2.10335.

[22] Berg, P., Becker, T., Martian, A., Danielle, P. K., \& Wingen, J. (2012). Motor control outcomes following Nintendo Wii use by a child with Down syndrome. Pediatric Physical Therapy, 24(1), 78-84. https://doi.org/10.1097/pep.0b013e31823e05e6

[23] What is Android OS? - Definition from Techopedia. Retrieved 11 January 2020, from https://www.techopedia.com/definition/14873/android-os

[24] Haas, J. K. (2014). A history of the unity game engine.

[25] Petty, J. (2019). What is Unity 3D \& What is it Used For? Retrieved 15 December 2019, from https://conceptartempire.com/what-is-unity/

[26] Code, V. Why Visual Studio Code? Retrieved 13 January 2020, from https://code.visual studio.com/docs/editor/whyvscode

[27] Stages of Game Testing | Alpha Testing | Beta Testing | Submission. (2019). Retrieved 8 December 2019, from https://ixiegaming.com/blog/three-major-stages-of-game-testing/

[28] 9 Different Types of Game Testing Techniques | Testbytes. (2019). Retrieved 8 December 2019, from https://www.testbytes.net/blog/types-of-game-testing/ 


\section{Authors}

Ceren Cubukcu received her PhD in Informatics at Istanbul University in Turkey. She won an award for best study in the field of innovation from Technology Development Foundation of Turkey with her PhD thesis in 2019. She has publications in the fields of digital entrepreneurship, risk and software project management and system analysis. She is currently working as an Assistant Professor at the Computer Engineering department of Maltepe University located in Istanbul, Turkey.

Murat Kaan Canbazoglu and Yigit Ozerdem are computer engineers graduated from the Computer Engineering Department of Maltepe University in 2020. They are mainly interested in software and mobile application development in Android platform. They are interested in programming languages of Unity, C\#, Java, PHP and SQL.

Article submitted 2020-06-25. Resubmitted 2020-07-28. Final acceptance 2020-07-29. Final version published as submitted by the authors. 